\title{
Caracterización epidemiológica de infección por SARS-CoV-2 del personal de salud de un hospital universitario en Santiago de Chile
}

\author{
Epidemiological characterization of infection by SARS-CoV-2 of the healthcare workers \\ of a university hospital in Santiago de Chile
}

Gustavo Saint-Pierre Contreras ${ }^{1}$, Francisco Silva Ojeda², Daniel Conei Valencia ${ }^{3,4}$ y Marcela Cifuentes Díaz

'Servicio de Laboratorio Clínico, Hospital Clínico Universidad de Chile. Santiago, Chile.
2Servicio de Laboratorio Clínico, Hospital Clínico Universidad de Chile, Santiago, Chile.
${ }^{3}$ Programa de Doctorado en Ciencias Morfológicas, Universidad de La Frontera. Temuco, Chile.
${ }^{4}$ Departamento de Ciencias de la Salud, Universidad de Aysén. Coyhaique, Chile.
${ }^{5}$ Comité de Prevención y Control de Infecciones Asociadas a la Atención de Salud y Epidemiología Hospitalaria, Hospital Clínico Universidad de Chile. Santiago, Chile.

Conflicto de interés: Ninguno.

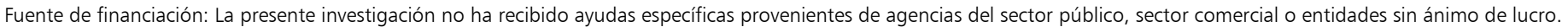

Recibido: 11 de agosto de 2020 (segunda versión 30 de marzo de 2021) / Aceptado: 3 de abril de 2021

\section{Resumen}

Introducción: El brote de SARS-CoV-2 originado en la provincia de Hubei en la República Popular China, se fue extendiendo aceleradamente en el mundo durante los primeros meses del año 2020. El 3 de marzo se notificó el primer caso en Chile; a los 17 días se notificó el primer caso de un Personal de Salud (PS) COVID-19 en nuestra institución. Objetivo: Describir las características demográficas y la incidencia de infección por SARS-CoV-2 en el PS de un hospital universitario de alta complejidad. Material y Método: Estudio retrospectivo de los casos de infección por SARS-CoV-2 del PS entre el 1 de marzo y 31 de mayo de 2020. Resultados: Hubo 273 casos positivos, con una incidencia de 5,8\% en el período en estudio. Al dividir los casos en personal clínico y no clínico se observó que sus incidencias fueron prácticamente idénticas $(5,8$ vs $5,7 \% \mathrm{p}=0,9430)$. El $88 \%$ de los funcionarios fue oligo-sintomático o asintomático al inicio del cuadro clínico y sólo $12 \%$ tuvo fiebre antes de la consulta médica. Conclusión: La incidencia reportada en el estudio fue alrededor de cinco veces la reportada en Wuhan. Al aplicar la definición de casos vigente, se perderían cuatro de cada cinco casos. Destaca que $88 \%$ del PS no presentaba criterios para ser considerado sospechoso, por lo que sería recomendable en el PS eliminar la fiebre como criterio para mejorar la pesquisa y trazar sus contactos de forma oportuna.

Palabras clave: SARS-CoV-2; trabajadores de la salud; COVID-19, brotes de enfermedades infecciosas; pandemia.

\section{Abstract}

Background: The SARS-CoV-2 outbreak originated in the Hubei province in China spread rapidly throughout the world during the first months of 2020. On March 3, the first case was reported in Chile; at 17 days the first case of COVID-19 healthcare worker (HCW) was notified in our institution. Aim: To describe the demographic characteristics and the incidence of SARS-CoV-2 infection in the HCW of a university hospital in Chile. Material and Method: Retrospective study of SARS-CoV-2 infection on HCW in a university hospital between March 1 and May 31, 2020. Results: There were 273 positive cases. In the period under study, we had an incidence of $5.8 \%$. When we separated the cases into clinical and non-clinical personnel, it was observed that their incidences were practically identical (5.8 vs. $5.7 \%$ p $=0.9430) .88 \%$ of the officials were oligosymptomatic or asymptomatic at the beginning of the clinical presentation and only $12 \%$ had a fever before the medical consultation. Conclusion: The incidence reported in the study was around 5 times that reported in Wuhan. If we apply the current definition of cases, we would lose 4 out of 5 cases. $88 \%$ of HPW did not present criteria to be considered suspicious, so it would be advisable in HCW to eliminate fever as a criterion to improve the research and trace their contacts on time.

Keywords: SARS-CoV-2 infection; healthcare workers; COVID-19; infectious disease outbreaks; pandemic. 


\section{Introducción}

$\mathrm{E}$ 1 brote actual del nuevo coronavirus SARS-CoV-2 ${ }^{1}$ se originó en la provincia de Hubei en la República Popular China, con una extensión acelerada en el mundo durante los primeros meses del año 2020,3. El 30 de enero, la Organización Mundial de la Salud (OMS), declaró una emergencia de salud pública de importancia internacional (ESPII), basada en las crecientes notificaciones de casos en distintos lugares de China, del continente asiático y fuera de éste 4 .

En estos primeros reportes se reconoce el agente causal, un nuevo beta-coronavirus, aislado y secuenciado desde un paciente de Wuhan, el 7 de enero de 2020, por científicos chinos ${ }^{5}$.

A mediados de febrero, la mayor carga de mortalidad se produjo en China, con un aumento de incidencia en el resto del continente asiático; también se reportaron los primeros casos positivos en Europa, inicialmente en Francia y Alemania ${ }^{1,2,6}$.

SARS-CoV-2 se propaga de persona a persona por la transmisión a través de gotitas, contacto con superficies $\mathrm{y}$, en ciertas ocasiones, por aerosoles ${ }^{7,8}$.

La misión de la OMS en China confirmó 2.055 casos de COVID-19 en el Personal de Salud (PS) en 476 hospitales chinos, al 20 de febrero del año 2020. La mayoría del PS infectado se informó en la región de Hubei ( $88 \%$ de los casos). Se desplegaron más de 40.000 sanitarios desde otras áreas de China para apoyar la respuesta en Wuhan. La OMS confirmó que, entre las infecciones adquiridas por el PS, la mayoría fueron identificadas temprano en el brote en Wuhan, cuando los suministros y la experiencia con la nueva enfermedad aún eran limitados ${ }^{9,10}$.

La incidencia de la infección por SARS-CoV-2 en el PS ha sido variada según el lugar de reporte. Aunque aún son escasos los informes a nivel mundial de la incidencia en PS, se destacó el estudio de Lai y cols., en Wuhan, que describió una tasa de infección de $1,1 \%$ durante el período comprendido entre el 1 de enero y 9 de febrero de $2020^{11}$. En los Países Bajos, en un hospital universitario de alta complejidad, se describe $4,2 \%$ del PS con un resultado positivo para coronavirus por la técnica de RT-PCR entre los días 7 a 12 de marzo de $2020^{2}$. Otro reporte de los Países Bajos, señaló 4,1\% de casos positivos en una serie de seis hospitales durante un período comprendido entre el 6 y 8 de marzo de $2020^{12}$. En el Reino Unido, en The Newcastle upon Tyne Hospitals National Health Service Fundation Trust, se realizó un testeo masivo a sus PS, a través de RT-PCR, donde se identificó $14 \%$ de casos entre el 10 y 31 de marzo $^{13}$. A la fecha, no se han publicado reportes en la región de Sudamérica, sobre incidencia en PS.

En Chile, la circulación de SARS-CoV-2 se inició el
3 de marzo de 2020 con el primer paciente reportado, un caso importado en un médico que retornaba de vacaciones por el Sudeste Asiático ${ }^{14}$. Con posterioridad a ello, la circulación viral aumentó rápidamente, razón por la cual la vigilancia de casos en el PS se volvió una necesidad para poder trazar y detectar los contactos estrechos. Desde el mes de febrero de 2020, y por orden de la Autoridad de Salud, se inició la preparación de los hospitales incluyendo la capacitación obligatoria en prácticas de control de infecciones, uso de equipo de protección individual (EPI) y lavado de manos ${ }^{15}$.

El propósito de nuestro estudio fue describir las características demográficas, categorización del origen del contagio y la incidencia de infección por SARS-CoV-2 en el PS de un hospital universitario de alta complejidad en Chile, incluyendo una categorización entre contagios comunitarios, aquellos asociados a la atención de salud, e indeterminados, en el período comprendido entre 1 de marzo y 31 de mayo del año 2020.

\section{Material y Método}

Se utilizó como definición de PS infectado, a "cualquiera persona que ejerza funciones, remuneradas o no, dentro del Hospital Clínico Universidad de Chile $(\mathrm{HCUCH})$ "; esto incluía a personal administrativo ${ }^{16,17}$ y que se hubiera diagnosticado con una infección por SARS-CoV-2 mediante una RT-PCR sigla en inglés para reacción de polimerasa en cadena con transcriptasa reversa positiva para dicho agente. Todo PS con sospecha de SARS-CoV-2 se podía realizar RT-PCR sin una restricción local. No se aplicó el protocolo inicial definido por el MINSAL al 8 de febrero de $2020^{15}$.

El HCUCH es un hospital universitario, perteneciente a la Universidad de Chile (universidad pública), clasificado como de alta complejidad, con 500 camas, que se ubica en la zona norte de la ciudad de Santiago de Chile, cuya población se caracteriza por tener un nivel de ingresos bajo y de hacinamiento alto ${ }^{18}$.

En el mes de marzo de 2020, en el HCUCH, se implementó la obligatoriedad de notificar al Comité de Prevención de Infecciones Asociadas a la Atención de Salud (CPC-IAAS), todo PS positivo para SARSCoV-2, con el objetivo de detectar oportunamente los contactos estrechos que requerían cuarentena (trazabilidad). De esta forma se obtuvo la información de la mayoría de los casos de PS infectado, lo que fue complementado con la pesquisa activa por parte del servicio de urgencia del HCUCH quienes también realizaron notificación de casos y, a fin del período, se incorporó una nómina obtenida automáticamente del cruce de base de datos de laboratorio clínico con Recursos Humanos del hospital. 
Para obtener el universo de PS durante el período de estudio, incluyendo a los médicos en programa de formación de especialidad, se utilizó la base de datos del Departamento de Recursos Humanos del establecimiento donde se incluía nombre, número de ID nacional, edad, sexo, cargo y área de desempeño dentro del hospital. La institución no cuenta con empresas anexas asociadas a la contratación de funcionarios.

Respecto de los casos, se realizó una base de datos con la información demográfica existente en el formulario de notificación de caso sospechoso perteneciente al sistema nacional de notificación obligatoria de COVID-19 llamado EPIVIGILA ${ }^{\circledR 19}$ y se complementó, en algunos casos, con información de la ficha clínica electrónica, cuando el PS fue atendido en el mismo hospital.

El PS se clasificó en dos grupos: PS de atención clínica y PS de unidades de apoyo. El grupo de atención clínica incluyó todos los servicios donde se atendió pacientes de cualquier nivel de complejidad, incluyendo laboratorios. Los únicos estudiantes que estuvieron presentes durante el período en estudio fueron los Médicos cursando postgrado de especialidad. Se suspendieron todas las actividades académicas presenciales desde la primera semana de marzo, incluyendo internados y todas las rotaciones de alumnos de pregrado; por tanto, no fueron considerados en el universo del estudio. El PS de unidades de apoyo incluyó todo lo demás, es decir, áreas como RRHH, finanzas, y oficinas sin atención de usuarios externos (pacientes), incluyendo el personal administrativo de todas las secciones, como las secretarias asociadas a los servicios.

Para la identificación de casos positivos a SARS-CoV-2, se utilizó la base de datos de laboratorio del hospital y para realizar la comparación sobre la positividad nacional, la información publicada por el Ministerio de Ciencia, Tecnología, Conocimiento e Innovación de Chile, construida con información emanada del Ministerio de Salud ${ }^{20}$.

El estudio fue aprobado por el Comité de Ética de Investigación del $\mathrm{HCUCH}$. Todos los datos fueron almacenados en forma segura.

\section{Método diagnóstico}

El método diagnóstico para personas atendidas en el HCUCH fue la RT-PCR (sigla en inglés para reacción de polimerasa en cadena en transcripción reversa) de SARS$\mathrm{CoV}-2$, de acuerdo a protocolos internacionales ${ }^{21}$. En el caso del PS que acudió a otro centro de salud del país, se le solicitó siempre la copia del examen de RT-PCR SARS-CoV-2 para considerarlo como caso confirmado. En Chile, todos los laboratorios requieren certificación en biología molecular para poder realizar este examen y la evaluación la realiza el Instituto de Salud Pública que corresponde al Centro Nacional de Referencia de Laboratorios $^{22}$.

\section{Análisis estadístico}

Se trata de un estudio descriptivo; por ello, no se realizaron cálculos de tamaño muestral. Para el cálculo de la incidencia en los casos positivos para SARS-CoV-2 se utilizó como numerador la cantidad de casos positivos y denominador el número total de personas según cargo, multiplicado por 100. Las variables continuas se describieron con medianas y rangos intercuartiles (IQR). Las variables categóricas se describieron como frecuencia y porcentajes. Se utilizaron las pruebas U de Mann-Whitney para el análisis de las variables continuas y $\chi^{2}$ para las variables categóricas. Para comparar la positividad de casos presentes en el HCUCH y los centros de vigilancia en la Región Metropolitana en las semanas epidemiológicas 10 a la 22, se realizó en base a escalas logarítmicas $\left(\log _{10}\right)$. Para la confección de la base de datos, se usó el programa Excel de Office $365^{\circledR}$ y para la aplicación de las pruebas estadísticas y realización de gráficos se utilizó el programa GraphPad Prism ${ }^{\circledR} 8.4$.

\section{Resultados}

En el mes de marzo de 2020, el HCUCH contaba con un total de 4.720 personas que cumplían con la definición de PS. De ellos, 532 eran médicos en formación de especialidad y sub-especialidad y el resto, 4.188 PS, con cualquier otro nexo contractual con la institución. Durante el período en estudio, se procesaron 7.431 muestras para RT-PCR de SARS-CoV-2, asociadas a una consulta respiratoria en urgencia o al acceso directo a laboratorio clínico mediante la unidad de toma de muestras. En el caso del PS, se tomaron 871 muestras a 843 PS que consultaron en urgencia o derivados por una central telefónica de médicos que atendía consultas exclusivamente a personal.

De las 871 RT-PCR de SARS-CoV-2 realizadas en el establecimiento a PS, 243 fueron positivas $(27,9 \%)$. Se sumaron a ellas, 30 RT-PCR realizadas en otros establecimientos y que pertenecían a PS del HCUCH. En total, hubo 273 casos reportados de infección por SARS-CoV-2, que corresponde a una incidencia de 5,8\% del total del PS.

De los 273 casos COVID-19, 182 (66,7\%) fueron mujeres y la mediana de edad en ambos sexos fue 37 años. Al comparar los casos positivos para SARS-CoV-2 y el resto de funcionarios, ya sea por edad, género o actividad que implique una atención clínica directa, no hubo diferencias estadísticamente significativas (Tabla 1). Sólo un contagio fue originado en un viaje fuera de Chile $(0,4 \%)$.

Del total de casos positivos, al analizar la frecuencia por cargo, los técnicos de enfermería fueron el estamento con más PS afectados con 90 casos $(33,1 \%$ del total del PS). No obstante, la unidad con mayor proporción de casos positivos fue Vigilancia, debido a un brote ocurrido en la unidad, con una incidencia de 38\% (18 casos de 47 


\begin{tabular}{|c|c|c|c|}
\hline & $\begin{array}{l}\text { Personal de Salud diagnosticado } \\
\text { con SARS-CoV-2 }\end{array}$ & $\begin{array}{l}\text { Personal de Salud que no tiene } \\
\text { diagnóstico de SARS-CoV-2 }\end{array}$ & Valor $p$ \\
\hline Número & 273 & 4.447 & \\
\hline \multicolumn{4}{|l|}{ Edad } \\
\hline \multicolumn{4}{|l|}{ Sexo } \\
\hline Hombre & $91(5,3)^{*}$ & $1.631(94,7)$ & $0,2654^{b}$ \\
\hline Mujer & $182(6,1)^{*}$ & $2.816(93,9)$ & \\
\hline \multicolumn{4}{|l|}{ Actividad } \\
\hline
\end{tabular}

Fuente: Elaboración propia con datos extraídos de Base de datos Personal de Salud (PS) COVID-19 HCUCH. RIQ: Rango intercuartílico. *Porcentaje de hombres y mujeres con SARS-CoV-2. ${ }^{* *}$ Incidencia de PS con atención clínica positivo para SARS-CoV-2. ${ }^{* *}$ Incidencia de PS de apoyo y administrativo positivo para SARS-CoV-2. Porcentaje (a) prueba estadística $U$ de Mann-Whitney. (b) prueba estadística chi cuadrado.

personas). El personal administrativo positivo alcanzó a 38 casos (13,9\% del total), enfermeras y médicos sumaron 32 casos, respectivamente (11,7\% del total cada uno) y 119 correspondientes a otros cargos. Al evaluar los resultados en los dos grupos previamente definidos, el PS con atención clínica directa da cuenta de 167 casos $(61,1 \%)$ y el PS de apoyo y administrativo, de 106 casos $(38,9 \%)$. La incidencia de cada grupo fue 5,8 y 5,7\%, respectivamente (Tabla 2).

Al revisar los registros de la notificación obligatoria $\left(\right.$ EPIVIGILA $^{\circledR}$ ), se pudo pesquisar que solo 33 casos $(12,1 \%)$, del total de 273 , cumplían con la definición de "caso sospechoso" vigente en el país en ese momento.

De los 273 casos, hubo 226 con síntomas y 47 que no tenían síntomas y se tomaron muestra sólo por interés personal. Los síntomas más frecuentes en la consulta fueron cefalea $(53,5 \%)$, seguido por mialgia y tos $(37,7$ y $33,3 \%$, respectivamente). En la Tabla 3 se describe el detalle de los síntomas y signos de la población sintomática (n: 226). En el período revisado, cuatro PS requirieron hospitalización (1,5\%), sin mortalidad asociada

Se pudo obtener antecedentes de co-morbilidades en aquellos que la refirieron en EPIVIGILA ${ }^{\circledR}$ o durante su consulta en el Servicio de Urgencia del establecimiento $(118 / 243=48,6 \%$ casos $)$. El tabaquismo fue los más frecuentes con 36 casos $(14,8 \%)$, seguidos de hipertensión arterial con 33 casos $(13,5 \%), 9$ casos de obesidad $(3,7 \%)$ y 8 casos de diabetes mellitus tipo 2 $(3,3 \%)$ (Tabla 4$)$.
Tabla 2. Incidencia de infección por SARS-CoV-2, por cargo, en el PS del HCUCH, entre 01 de marzo y 31 de mayo 2020 ( $n^{\circ}$ positivos: 273; total: 4.720) [Incidencia por estamento]

\begin{tabular}{lcc}
\hline Cargo & $\begin{array}{c}\mathbf{n} \text { de positivos } \\
\text { por cargo [\%] }\end{array}$ & $\begin{array}{c}\mathbf{n} \text { total } \\
\text { por cargo }\end{array}$ \\
\hline Técnicos paramédicos & $90[9,8]$ & 919 \\
\hline Administrativos & $38[4,5]$ & 851 \\
\hline Médicos staff & $13[2,1]$ & 615 \\
\hline Médicos en programa de formación de especialidad y & $19[3,6]$ & 532 \\
subespecialidad & $13[2,6]$ & 508 \\
\hline Otros auxiliares & $32[6,9]$ & 466 \\
\hline Enfermera(o) & $10[5,5]$ & 181 \\
\hline Personal de aseo & $23[13,6]$ & 169 \\
\hline Otros técnicos & $2[1,7]$ & 120 \\
\hline Tecnólogo médico & $5[4,2]$ & 117 \\
\hline Kinesiólogo & $4[6,3]$ & 63 \\
\hline Matrona/ón & $18[38,3]$ & 47 \\
\hline Vigilantes* & $1[2,3]$ & 43 \\
\hline Odontólogo & $2[4,7]$ & 43 \\
\hline Terapeuta ocupacional & $1[3,7]$ & 27 \\
\hline Nutricionista & $2[11]$ & 19 \\
\hline Químico farmacéutico & & \\
\hline
\end{tabular}

Fuente: Elaboración propia con datos extraídos de Base de datos Personal de Salud COVID-19 HCUCH. *11 de 19 casos fueron parte de un brote que afectó vigilantes que compartían áreas de alimentación y descanso. 
Tabla 3. Frecuencia de síntomas y signos descritos en el PS del HCUCH positivo para SARS-CoV-2, entre 01 de marzo y 31 de mayo 2020, del total de PS sintomático $(n=226)$

\begin{tabular}{lcc}
\hline Síntomas y signos & n de casos & Frecuencia \\
\hline Cefalea & 146 & $65 \%$ \\
\hline Mialgia & 103 & $46 \%$ \\
\hline Tos & 91 & $40 \%$ \\
Odinofagia & 78 & $35 \%$ \\
\hline Sensación febril & 60 & $27 \%$ \\
\hline$T^{\circ}>37,8^{\circ} \mathrm{C}$ & 33 & $15 \%$ \\
\hline Anosmia & 29 & $13 \%$ \\
\hline Otros & 18 & $8 \%$ \\
\hline Ageusia & 15 & $7 \%$ \\
\hline Diarrea & 15 & $7 \%$ \\
\hline Dolor abdominal & 5 & $2 \%$ \\
\hline
\end{tabular}

Fuente: Tabla elaboración propia con datos extraídos de Base de datos Personal de Salud COVID-19 HCUCH.

Tabla 4. Co-morbilidades reportadas por PS que fueron positivos para SARS-CoV-2, entre 01 de marzo y 31 de mayo 2020. Porcentaje calculado sobre 243 PS que consultaron en servicio de urgencia $\mathrm{HCUCH}$

\begin{tabular}{lcc}
\hline Co-morbilidades & n de casos & Frecuencia (\%) \\
Tabaquismo & 36 & $14,8 \%$ \\
Hipertensión arterial & 33 & $13,5 \%$ \\
Obesidad & 9 & $3,7 \%$ \\
Diabetes mellitus tipo 2 & 8 & $3,3 \%$ \\
Resistencia a insulina & 7 & $2,8 \%$ \\
Asma bronquial & 6 & $2,4 \%$ \\
Inmunosupresión & 4 & $1,6 \%$ \\
Otras & 15 & $6,2 \%$ \\
\hline Fuente: Tabla elaboración propia con datos extraídos de Base de datos Personal de Salud \\
COVID-19 HCUCH.
\end{tabular}

Durante el período del estudio el CPC-IAAS efecuó la trazabilidad de todos los casos confirmados del PS, de modo de identificar a aquellos contactos estrechos que cumplían el riesgo de acuerdo a definiciones de la autoridad sanitaria. Del total de PS notificados (n: 273), se logró trazar oportunamente $(<48$ h) a 271. Se obtuvo 203 contactos estrechos en un rango de 0 a 60 personas por caso. El primer PS COVID positivo del hospital, se pesquisó el 21 de marzo de 2020, en un médico de la unidad de cuidados intensivos. Hasta esa fecha no se había hospitalizado paciente alguno por
COVID-19 en el HCUCH, por lo que este primer caso fue atribuido a un origen comunitario. Este PS dejó 60 contactos estrechos repartidos entre dos equipos de turno médicos y de enfermería de intensivo y dos grupos de capacitación en precauciones estándar y uso de elementos de protección personal. Hasta esa fecha no se habían suspendido aún las reuniones clínicas, capacitaciones presenciales y tampoco se había implementado el uso de mascarilla universal. Los casos posteriores al descrito, y luego de haber implementado medidas estrictas, dejaron un rango de 0 a 11 contactos con una mediana de 0 . De los contactos intra-hospitalarios de PS (n: 226) que tuvieron que realizar cuarentena, sólo nueve se transformaron en casos positivos 3,9\% (9/226). Estos casos positivos se agruparon según el origen del contagio: 6,5\% (19/273) de los casos fue laboral no asociado a la atención de salud, es decir, PS administrativo que se contagió en oficinas sin atención de público y sin contacto con PS clínico, como fuera el caso de R.R.H.H cuyas oficinas están separadas de la infraestructura hospitalaria. A 11,7\% (32/273) se les consideró asociados a la atención de salud, ya fuese por contagio desde un paciente o PS clínico prestando funciones en el período pre-sintomático $\mathrm{u}$ oligo-sintomático no pesquisado.

Casos de adquisición extra hospitalaria, con fuente conocida de contagio confirmado. ya fuese intra-domiciliario, familiar, actividades comunitarias entre otras fueron $23,8 \%(65 / 273)$.

Para finalizar, tuvimos $57,5 \%$ de PS indeterminados (157/273).

En el período en estudio se observaron tres brotes asociados a contagios de PS:

- En el Servicio de Vigilancia hubo 11 involucrados, con un caso primario que tenía antecedentes de un familiar con sintomatología respiratoria.

- En Maternidad hubo ocho PS positivos, en que el contagio probablemente ocurrió al compartir en el área de alimentación o al compartir automóvil para el desplazamiento al hospital.

- Un brote ocurrió en la Unidad de Neonatología, en el área de alimentación y descanso, involucrando a ocho PS.

Finalmente, respecto a la tasa de positividad de exámenes RT-PCR para SARS-CoV-2 tomados al PS procesados en el laboratorio del $\mathrm{HCUCH}$, en la Tabla Suplementaria 1 se muestra la positividad para SARSCoV-2 por semana epidemiológica, observándose que los casos positivos en el PS HCUCH empezaron a aparecer en la SE 16 (8\%) ascendiendo hasta un máximo de $47 \%$ en la SE 22 mientras en la población consultante al HCUCH durante la SE 12 el 6\% de muestras fueron positivas lo que aumentó hasta $51 \%$ en la SE 22 (Figura 1-Tabla suplementaria 1). 


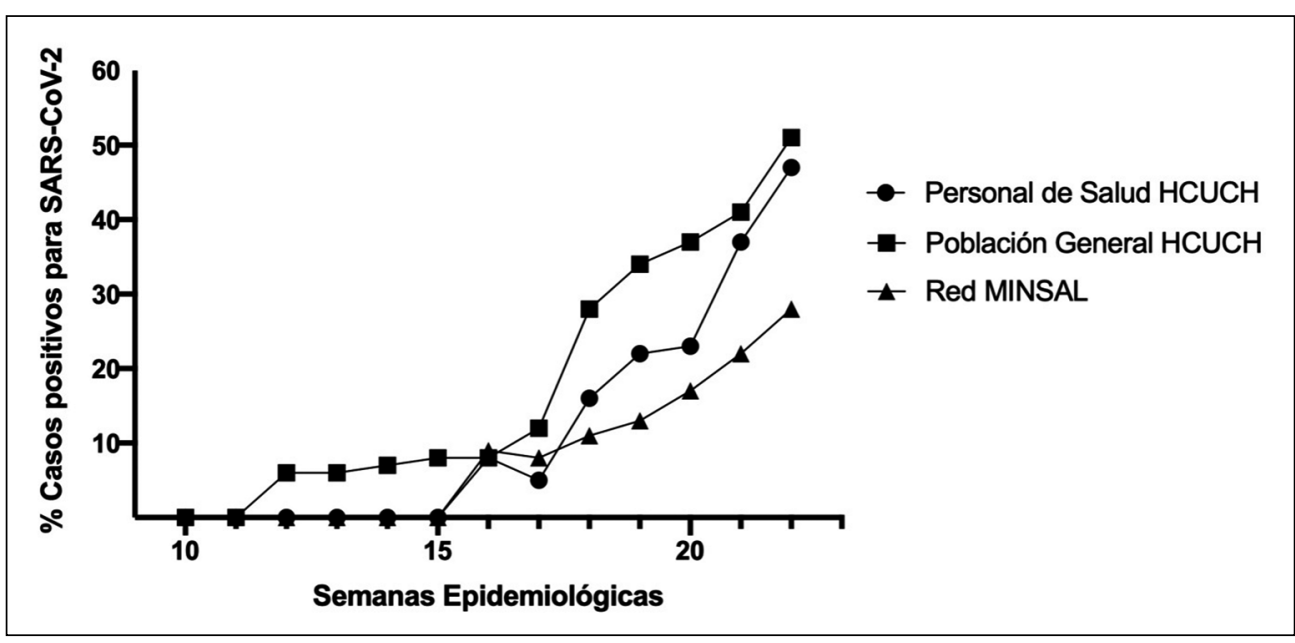

Figura 1. Comparación de la tasa de positividad, por semana epidemiológica, de infección por SARS-CoV-2 en la población general del país (Lab Red MINSAL), público en general atendido en el $\mathrm{HCUCH}$ y Personal de Salud atendido en el $\mathrm{HCUCH}$, entre 01 de marzo al 31 de mayo de 2020.

\section{Discusión}

Nuestro estudio se basó en los datos recolectados en un hospital universitario de alta complejidad de Santiago de Chile. La incidencia de infección por SARS-CoV-2 en el PS fue de 5,8\%, y no encontramos diferencia significativa entre personal clínico $(5,8 \%)$ y personal de apoyo $(5,7 \%)$. Esta incidencia fue mayor a la reportada en el brote inicial en Wuhan, China $(1 \%)^{8}$ o la reportada en Países Bajos $(4,6 \%)^{2}$ pero menor a la evaluada en Newcastle, Inglaterra $(14 \%)^{13}$. Todas las instituciones citadas no desglosaron sus datos entre contagio asociado a la atención de salud o comunitario. Lamentablemente, a la fecha, no existen datos sudamericanos o en el país que permitan compararla con realidad local.

Llama la atención que dentro de los casos en el PS, la frecuencia de asintomáticos, sumada a la de oligosintomáticos cuyos síntomas no eran suficientes para categorizarlos como caso sospechoso, correspondió a 88\% del total del PS con infección por SARS-CoV-2, dejando sólo a 33 (12\%) cumpliendo la definición de caso exigida en muchos establecimiento de salud públicos de Chile, para la realización de la RT-PCR. Durante el período en estudio no se realizó búsqueda activa de casos, todo el PS consultante lo realizó por decisión personal y asistió a los canales de atención definidos previamente.

Los hospitales públicos en Chile, por décadas han contado con un presupuesto limitado, en el cual no se ha incorporado la biología molecular como la base de los estudios virológicos. Hasta inicios de la pandemia, la biología molecular y los exámenes de RT-PCR eran derivados al centro nacional de referencia. Por la pandemia se debió implementar la técnica en muchos hospitales; aun así, existían limitaciones a la toma de los exámenes, debiendo cumplir la definición vigente. Ésta restringía la toma de muestra aquellos que tuvieran temperatura mayor a $37,8^{\circ} \mathrm{C}$ y al menos un síntoma como odinofagia, tos, mialgia o disnea ${ }^{23,24}$, dejando a muchos afebriles sin acceso al examen. En el HCUCH no existió esta restricción y se tomaba examen a cualquier paciente consultante que tuviera síntomas descritos en literatura médica hasta el momento, incluso a los asintomáticos que lo solicitaran. La toma de muestra sin la presencia de fiebre permitió aumentar el diagnóstico en el PS del $\mathrm{HCUCH}$, lo que fue concordante con lo estudiado en Países Bajos ${ }^{2}$, en que sugirieron ser menos estricto con la definición de caso sospechoso al momento de la toma de la RT-PCR y donde $51 \%$ de los trabajadores no cumplieron con la definición de caso. Eso refuerza las recomendaciones de la OMS sobre extremar la capacidad de testeo ${ }^{25}$.

Dentro de los casos sintomáticos en nuestro PS, la frecuencia de fiebre fue baja (15\%). A la fecha no existían estudios sudamericanos que describieran la sintomatología en el PS, pero los síntomas son disímiles a los observados en estudios en Europa y China donde había más de $50 \%$ de casos febriles ${ }^{2,8}$. Esto se podría explicar debido a que en Sudamérica ya era conocida la enfermedad y por el temor a contraerla, podría haber aumentado la consulta médica precoz frente al inicio de los síntomas, lo que queda demostrado con el alto porcentaje de PS oligo-sintomático que resultó positivo en nuestra serie $(193 / 273=70 \%)$.

La Tabla suplementaria 1 muestra una comparación entre la tasa de positividad en los exámenes realizados en la población general del país, la población general que consultó en el HCUCH y el PS que consultó en el HCUCH (n: 235). Se puede observar que la positividad en el PS fue inferior a la de la población general-HCUCH, aunque superior a la población diagnosticada en los hospitales públicos de Santiago. Esto pudo deberse a que hubo 
grandes diferencias temporales en la ocurrencia de casos en las distintas comunas de la capital del país, siendo la del HCUCH una de las primeras. En el PS se produjo un aumento progresivo en la tasa de positividad, con una curva similar a la observada en la población general$\mathrm{HCUCH}$, sin alzas discordantes que sugirieran brotes intrahospitalarios. Una causa probable al mayor aumento de casos en el PS HCUCH puede ser que se utilizó una definición distinta a la operativa por MINSAL en dicho minuto, que permitía la toma de PCR sin cumplir con todos los síntomas solicitados.

Al igual que el grupo de Kluytmans-van den Bergh², con el objetivo de mejorar la sensibilidad diagnóstica para la infección por este agente, en base a nuestros resultados, es planteable modificar los requisitos (o criterios diagnósticos) para solicitar RT-PCR para SARS-CoV-2 al menos en el PS (es la población que se estudió, no se analizó la población general), pudiendo extrapolarse también esta conducta a la población general. Al mejorar la pesquisa, se puede disminuir el número de PS pre-sintomático, asintomático y oligo-sintomático no diagnosticados que, de mantener su vida normal, continuarían contagiando a otras personas o provocando brotes asociados a la atención de salud. De este modo se pueden aislar precozmente y trazar sus contactos de forma oportuna.

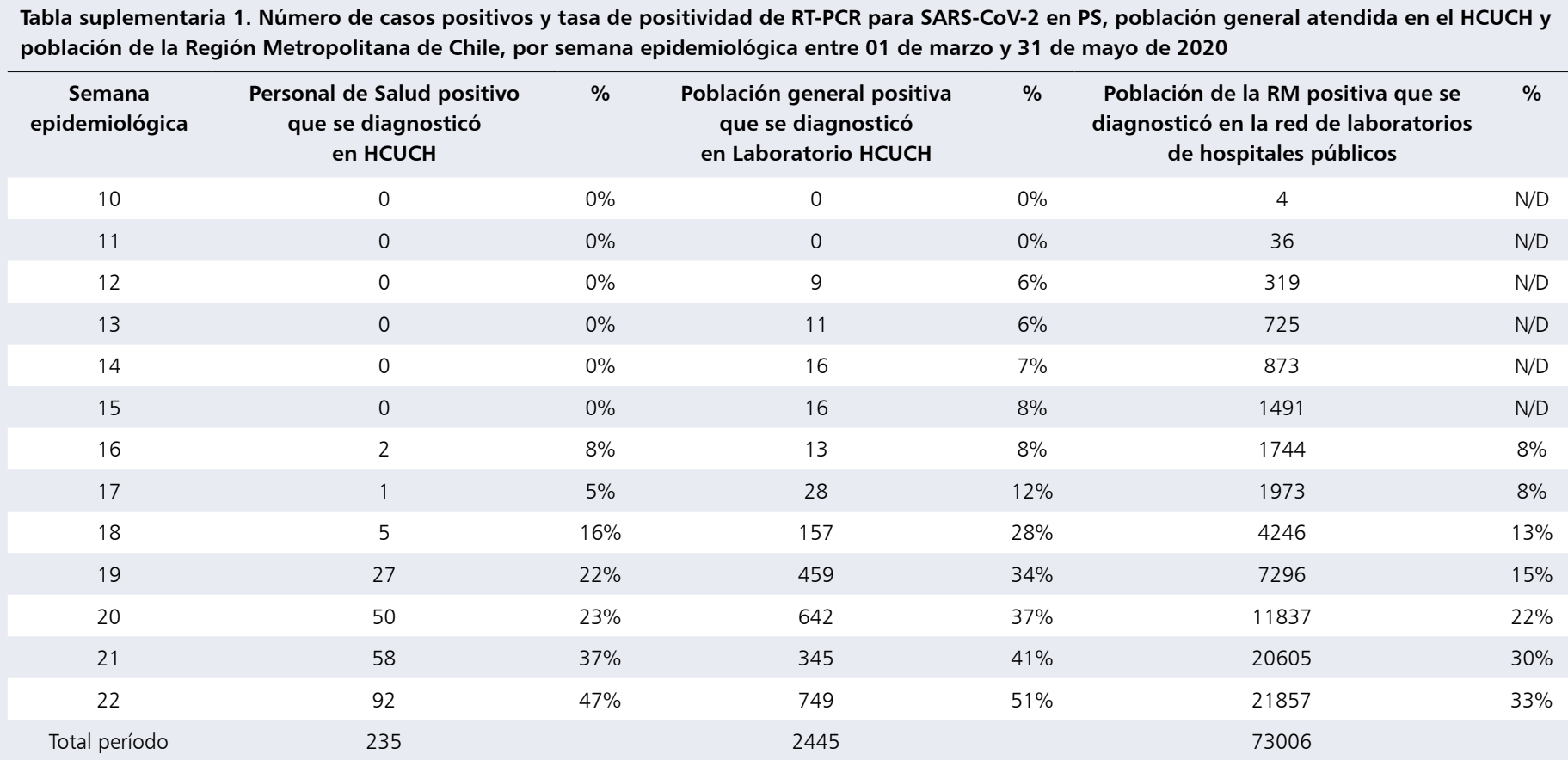

Fuente: Tabla de elaboración propia con datos obtenidos del Ministerio de Ciencia y Base de datos Personal de Salud HCUCH COVID-19 ${ }^{20}$. N/D Dato no disponible.

\section{Referencias bibliográficas}

1.- Velavan T P, Meyer C G. The COVID-19 epidemic. Trop Med Int Health. 2020; 25(3): 278-280. doi: 10.1111/tmi.13383.

2.- Kluytmans-van den Bergh M F, Buiting A G, Pas S D, Bentvelsen R G, Bijllaardt W $\mathrm{V}$, van Oudheusden A J, et al. Prevalence and clinical presentation of health care workers with symptoms of coronavirus disease 2019 in 2 Dutch hospitals during an early phase of the pandemic. JAMA Netw Open. 2020; 3 (5): e209673. doi: 10.1001/ jamanetworkopen.2020.9673.

3.- Dong E, Du H, Gardner L. An interactive web-based dashboard to track COVID-19 in real time. Lancet Infect Dis 2020; 20: 5533-4. https://doi.org/10.1016/S1473-3099(20)301201.

4.- World Health Organization. (30 de enero de 2020). Novel coronavirus(2019-nCoV) situation Report 10. [Fecha acceso $30 \mathrm{de}$ julio 2020] Disponible en: https://www. who.int/docs/default-source/coronaviruse/ situation-reports/20200130-sitrep-10-ncov. pdf?sfvrsn=d0b2e480_2.
5.- Guo Y R, Cao Q D, Hong Z S, Tan Y Y, Chen $\mathrm{S} \mathrm{D}$, Jin $\mathrm{H} \mathrm{J}$, et al. The origin, transmission and clinical therapies on coronavirus disease 2019 (COVID-19) outbreak - an update on the status. Military Med Res 2020; 7(1): 11. https:// doi.org/10.1186/s40779-020-00240-0.

6.- Spiteri G, Fielding J, Diercke M, Campese C, Enouf V, Gaymard A, et al. First cases of coronavirus disease 2019 (COVID-19) in the WHO European Region, 24 January to 21 February 2020. Euro Surveill. 2020; 25 (9): pii=2000178. https://doi.org/10.2807/15607917.ES.2020.25.9.2000178. 
7.- Wang H, Li X, Li T, Zhang S, Wang L, $\mathrm{Wu} \mathrm{X}$, Liu J. The genetic sequence, origin, and diagnosis of SARS-CoV-2. Eur J Clin Microbiol Infect Dis 2020; 19: 1629-35. https:// doi.org/10.1007/s10096-020-03899-4.

8.- Li H, Liu S M, Yu X H, Tang S L, Tang C K. Coronavirus disease 2019 (COVID-19): current status and future perspectives. Int J Antimicrob Agents 2020; 55(5): 105951. https://doi. org/10.1016/j.ijantimicag.2020.105951.

9.- World Health Organization (24 de febrero de 2020). Report of the WHO-China Joint Mission on Coronavirus Disease 2019 (COVID-19. [Fecha acceso 17 de julio 2020] Disponible en: https://www.who.int/docs/default-source/ coronaviruse/who-china-joint-mission-oncovid-19-final-report.pdf.

10.- Wong S C Y, Kwong R T-S, Wu T C, Chan J W M, Chu M Y, Lee S Y, et al.

Risk of nosocomial transmission of coronavirus disease 2019: an experience in a general ward setting in Hong Kong. J Hosp Infect. 2020; 105(2): 119-27. doi: 10.1016/j. jhin.2020.03.036.

11.- Lai X, Wang M, Chuan Q, Tan L, Ran L, Chen D, et al. Coronavirus disease 2019 (COVID-19) infection among health care workers and implications for prevention measures in a tertiary hospital in Wuhan, China. JAMA Netw Open 2020; 3 (5): e209666. https://doi.org/10.1001/ jamanetworkopen.2020.9666.

12.- Reusken C B, Buiting A, Bleeker-Rovers C, Diederen B, Hooiveld M, Friesema I, et al. Rapid assessment of regional SARSCoV-2 community transmission through a convenience sample of healthcare workers, the Netherlands, March 2020. Euro Surveillance: Bulletin Europeen Sur Les Maladies Transmissibles = European
Communicable Disease Bulletin 2020; 25(12): 2000334. https://doi.org/10.2807/1560-7917. ES.2020.25.12.2000334.

13.- Hunter E, Price D A, Murphy E, Schim van der Loef I, Baker K F, Lendrem D, et al. First experience of COVID-19 screening of health-care workers in England. Lancet 2020; 395(10234): e77-78. doi: 10.1016/S01406736(20)30970-3.

14.- MINSAL [Internet]. 3 de marzo de 2020; [Fecha acceso 31 de julio de 2020] Disponible en: https://www.minsal.cl/ministerio-de-saludconfirma-primer-caso-de-coronavirus-en-chile/

15.- MINSAL [Internet]. 8 de febrero de 2020; [Fecha acceso 31 de julio de 2020] Disponible en: https://www.minsal.cl/wp-content/ uploads/2020/02/1724518_alerta_sanitaria coronavirus.pdf.

16.- SUCESO, Imparte instrucciones respecto a la calificación del origen de la enfermedad COVID-19 que afecte al personal de establecimientos de salud y aquellos que han sido determinados como contactos estrechos. [Internet]. 27 de abril de 2020; [Fecha acceso 31 de julio de 2020]. Disponible en: https://www.falmed.cl/ falmed/especial-covid-19/suseso-determinaque-covid-19-debe-ser-calificada-comoenfermedad.

17.- Joseph B, Joseph M. The health of the healthcare workers. Indian J Occup. Environ Med. 2016; 20(2): 71-2. doi:10.4103/00195278.197518 .

18.- Razmilic $S$, Inmigración, vivienda y territorio En Aninat I, Vergara R, editores. Inmigración en Chile. Una mirada multidimensional. Santiago, Centro de Estudios Públicos, 2019, p 101-47.

19.- Ley Chile [Internet]. 23 de abril de 2020; [Fecha acceso 16 de junio de 2020]
Disponible en: https://www.leychile.cl/ Navegar?idNorma $=1141549$.

20.- Ministerio de Ciencia, Tecnología, Conocimiento e Innovación [Internet]. 10 de junio de 2020; [Fecha accesos 20 de julio de 2020] Disponible en: https://github.com/ MinCiencia/Datos-COVID19/blob/master/ output/producto7/PCR.csv.

21.- WHO [Internet]. 17 de enero de 2020. Laboratory testing of 2019 novel coronavirus (2019-nCoV) in suspected human cases: interim guidance. [Fecha acceso: 28 de junio de 2020] Disponible en: https://www.who. int/publications/i/item/laboratory-testing-of2019-novel-coronavirus-(-2019-ncov)-insuspected-human-cases-interim-guidance-17january-2020.

22.- MINSAL [Internet]. 12 de marzo de 2020 [Fecha acceso 28 de junio de 2020] Disponible en: http://www.ist.cl/wpcontent/uploads/2020/03/ORD-B1-N-845ACTUALIZACI\%C3\%93N-DE-ALERTA-YREFUERZO-COVID-19-MINSAL.pdf.

23.- MINSAL [Internet]. 23 de marzo de 2020; [Fecha acceso 28 de junio de 2020] Disponible en: https://www.minsal.cl/wp-content/ uploads/2020/04/Ord.-B51-N\%C2\%BA933. pdf.

24.- Diario Oficial [Internet]. 30 de mayo de 2020; [Fecha acceso 16 de junio de 2020] Disponible en: https://www.diariooficial.interior.gob.cl/ publicaciones/2020/06/09/42676/01/1771191. pdf.

25.- WHO [Internet]. 16 de marzo de 2020. WHO Director-General's opening remarks at the media briefing on COVID-19 [Fecha acceso 31 de julio de 2020]. Disponible en: https:// www.who.int/dg/speeches/detail/who-directorgeneral-s-opening-remarks-at-the-mediabriefing-on-covid-19---16-march-2020. 